\title{
Morphometric Study of the Role of Pulmonary Arterial Flow in Fetal Lung Growth in Sheep
}

\author{
LINDA D. WALLEN, STEVEN F. PERRY ${ }^{1}$, JAMES T. ALSTON, AND JOHN E. MALONEY ${ }^{2}$ \\ with the technical assistance of Colleen S. Kondo and Yoshimi Takahashi \\ Reproductive Medicine Research Group, University of Calgary Medical Centre, \\ Calgary, Alberta, Canada T2N $4 N 1$
}

\begin{abstract}
Pulmonary hypoplasia has been associated with absent or hypoplastic pulmonary artery in four cases in humans. Despite these reports, the effects of decreased pulmonary arterial flow on fetal lung growth have not been adequately studied. This study defines the effects of left pulmonary artery (LPA) ligation on fetal lung growth in sheep by comparing morphometrically determined pulmonary volumes from LPA-ligated, sham-operated, and unoperated control fetuses. LPA ligation $(n=5)$ or sham operation $(n=4)$ was performed at 105 - to 114-d gestation. At 140-d gestation these fetuses were delivered and the lungs were intratracheally fixed for light microscopy. At $112 \mathrm{~d}(n=4)$ and at $140 \mathrm{~d}(n=4)$, unoperated control fetuses were similarly delivered. Absolute pulmonary volumes were then measured using standard stereologic methods. Normal growth of the left lung from 112 to $140 \mathrm{~d}$ resulted in significant increases in wet and dry wt, displacement volume, and volumes of future airspace and capillary contents. LPA ligation caused significant decreases in left lung wet and dry wt, displacement volume, and in absolute volumes of fine nonparenchyma, future airspace, parenchymal tissue, and capillary contents compared to sham-operated and 140-d controls. Parenchymal tissue volume was also less than in 112-d controls. In addition, lung wt, displacement volume, and future airspace volume were significantly decreased in sham-operated fetuses compared to 140-d controls. The effects of LPA ligation on bronchial collateral circulation and factors known to affect lung growth (i.e. lung fluid volume) remain to be determined. Clearly, during the canalicular and alveolar stage of fetal lung development, pulmonary arterial flow is necessary for normal lung growth. (Pediatr Res 27: 122-127, 1990)
\end{abstract}

\section{Abbreviation}

LPA, left pulmonary artery

Pulmonary hypoplasia is a common abnormality in newborn infants dying of respiratory causes, and has been reported to be present in $14-21 \%$ of neonatal autopsies $(1,2)$. Despite the magnitude of this problem and its importance in successful

Received January 9, 1989; accepted October 2, 1989.

Correspondence Linda D. Wallen, M.D., Department of Pediatrics, HMRB 203 , University of Calgary Medical Centre, 3330 Hospital Drive NW, Calgary, Alberta, Canada T2N 4Ni.

Supported in part by The Alberta Lung Association, The University of Calgary, The Christie Unit for the Study of Human Reproduction, and Deutsche Forschungsgemeinschaft (S.F.P.).

${ }^{1}$ Present address Department of Biology, University of Oldenburg, Federal Republic of Germany.

${ }^{2}$ Present address Curtin University of Technology, Perth 6001, W. A., Australia. neonatal respiratory adaptation, its causes are not clearly defined. Factors that are known to influence fetal lung growth (3) include intrathoracic space $(4,5)$, amount of amniotic fluid $(6)$, the balance of fluid and pressure within the lungs $(7,8)$, and the incidence and amplitude of fetal breathing movements $(9,10)$. Although pulmonary hypoplasia and aberrant lung growth are associated with decreased pulmonary arterial flow in humans $(11,12)$, the contribution of pulmonary arterial flow to fetal lung growth has not been adequately studied $(13,14)$.

Fetal lung growth and development has been extensively investigated in sheep $(3-5,7-10,13,15)$. Alcorn et al. (15) have provided information about the stages of lung growth in fetal sheep. Their data indicate that during the late canalicular and early alveolar stages (from 110-140 d gestation), lung wet wt doubles, the percentage of future airspace volume increases by $30 \%$, and alveolar surface area doubles (15). There are no data concerning pulmonary blood volume or absolute morphometric volumes in any of the studies of fetal lung growth in sheep.

Our study morphometrically determines lung volumes in fetal sheep during the late canalicular and early alveolar stages of lung development and uses this normal data to determine the role of pulmonary arterial flow in fetal lung growth.

\section{MATERIALS AND METHODS}

Twenty-one Western breed fetal sheep were studied at 105 to $141 \mathrm{~d}$ of gestation; the date of conception was known within 2 $\mathrm{d}$. The fetuses were divided into four groups: LPA ligation, sham operation, 112-d controls, and 140-d controls.

Thirteen fetuses had surgery performed at 105- to 114-d gestation: eight LPA ligated and five sham operated. The mean gestational age at surgery was $111 \mathrm{~d}$ in both groups. Three fetuses with LPA ligation and one sham-operated fetus delivered spontaneously before lung fixation at 140-d gestation. Histologic specimens from the first LPA-ligated fetus were not available. Thus, lung wt and volumes for five LPA-ligated fetuses and four fetuses in all other groups and morphometric data for four fetuses in each group are presented.

Surgical preparation. At 105- to 114-d gestation with the ewe under general anesthesia (halothane), a left lateral flank incision and hysterotomy was done to expose the fetal thorax. Care was taken to prevent the loss of amniotic fluid. A left thoracotomy was performed through the fourth intercostal space to reveal the LPA (postductus arteriosus). Taking care to disturb the lung tissue as little as possible, the LPA was isolated and ligated in eight fetuses (LPA ligation group). Five fetuses had the LPA exposed and isolated but not ligated (sham-operated group). Upon closure of the thoracotomy the fetus was replaced in the amniotic cavity and Penicillin G $50000 \mathrm{U}$ was put into the amniotic fluid. If twins were present, one fetus underwent LPA ligation and the other sham operation. After recovery from anesthesia the ewe was placed in a pen with food and water 
provided ad libitum. The ewe was treated with intramuscular penicillin and streptomycin for $7 \mathrm{~d}$ postoperatively.

At 139- to 141-d gestation, a repeat cesarean section was done under general anesthesia to deliver the fetus. Through a midline incision the fetal head and neck were exposed. The trachea was intubated with a $3.5-\mathrm{mm}$ endotracheal tube and as much lung fluid as possible was removed and replaced with an equal volume of buffered glutaraldehyde fixative $(\mathrm{pH} 7.2-7.4$, osmolarity $=$ 350 mosmol) (15). Simultaneously, $\mathrm{KCl}$ was injected into a fetal umbilical vessel as the cord was clamped; the fetus was delivered and weighed. Groups of four unoperated fetuses at $112 \mathrm{~d}$ and at $140 \mathrm{~d}$ were similarly delivered to serve as controls. This protocol was reviewed and approved by the University of Calgary Animal Care Committee.

Preparation and evaluation of lung tissue. The fixed lungs were quickly removed and total occlusion or patency of the LPA was documented. All fetuses in the LPA-ligated group had an occluded LPA that would not admit a $1-\mathrm{mm}$ probe. Right and left lungs were weighed and the volume of normal saline displaced was measured. This displacement volume served as a standard for the calculation of absolute morphometric volumes. Dry wt were measured on previously weighed samples of randomly chosen, diced cubes from each lung after $96 \mathrm{~h}$ in a drying oven.

After $1-2 \mathrm{~h}$ in glutaraldehyde fixative, specimens were prepared for morphometric analysis according to the methods of Weibel $(16,17)$. The left lung was divided into upper and lower lobes; each lobe was cut into five equal slices and photographed. Each lobe was then cut into cubes $1.5 \mathrm{~cm}$ on a side and three specimens from the upper lobe and four from the lower lobe were randomly selected for further analysis. One section of each of the specimens was dehydrated and embedded in Historesin. In addition, $1-\mathrm{mm}^{3}$ dices were postfixed in $1 \%$ osmium tetroxide, en bloc stained with uranyl acetate, alcohol dehydrated, and embedded in Spurr.

The lung was evaluated as parenchyma and nonparenchyma. Parenchyma included: future airspace-air in saccules, alveolar ducts, and alveoli, and parenchymal tissue-airspace wall and structures $<30-\mu$ m diameter adjacent to airspace (blood vessel or connective tissue bands). Capillary contents included only the space contained by capillary endothelium and not the endothelial cell volume. Nonparenchyma included all other structures: airways with their connective tissue sheaths and luminal air, connective tissue bands $>30-\mu \mathrm{m}$ diameter, and blood vessels $>30$ $\mu \mathrm{m}$ diameter.

To determine absolute volumes of all tissue components, a four level sampling cascade was used $(16,18)$ (Fig. 1). Each level was defined by the tissue component that could be accurately resolved and measured at a given magnification. After a given component was measured, it was excluded from the next levels of sampling by setting an upper limit on the size of objects included. Level I was gross examination of the slides of whole lung slices and allowed accurate resolution of coarse nonparenchyma $>1 \mathrm{~mm}$. Therefore, the magnification for level II (objective $=2.5 \times$ ) was chosen to allow objects $\leq 1 \mathrm{~mm}$ to be measured in each microscope field. At this magnification, coarse nonparenchyma $>300 \mu \mathrm{m}-1 \mathrm{~mm}$ could be accurately defined using standard morphometric test lattices (17). To allow fine nonparenchyma $\leq 300 \mu \mathrm{m}$ to be measured in each microscope field, a $40 \times$ objective was used for level III. At this magnification, the volume density of future airspace and parenchymal tissue could also be accurately determined.

Light microscopic examination for levels II-IV was done using two sections from the upper lobe and three from the lower lobe. Negative prints of test lattices were placed on a light box and optically superimposed onto the histologic section using a drawing tube. For analysis of coarse nonparenchyma $300 \mu \mathrm{m}-1 \mathrm{~mm}$ (level II) entire Historesin sections were examined. Volume density of fine nonparenchyma $30-300 \mu \mathrm{m}$, future airspace, and parenchymal tissue (level III), as well as capillary contents (level IV), were determined using Spurr-embedded sections cut to 0.5 -

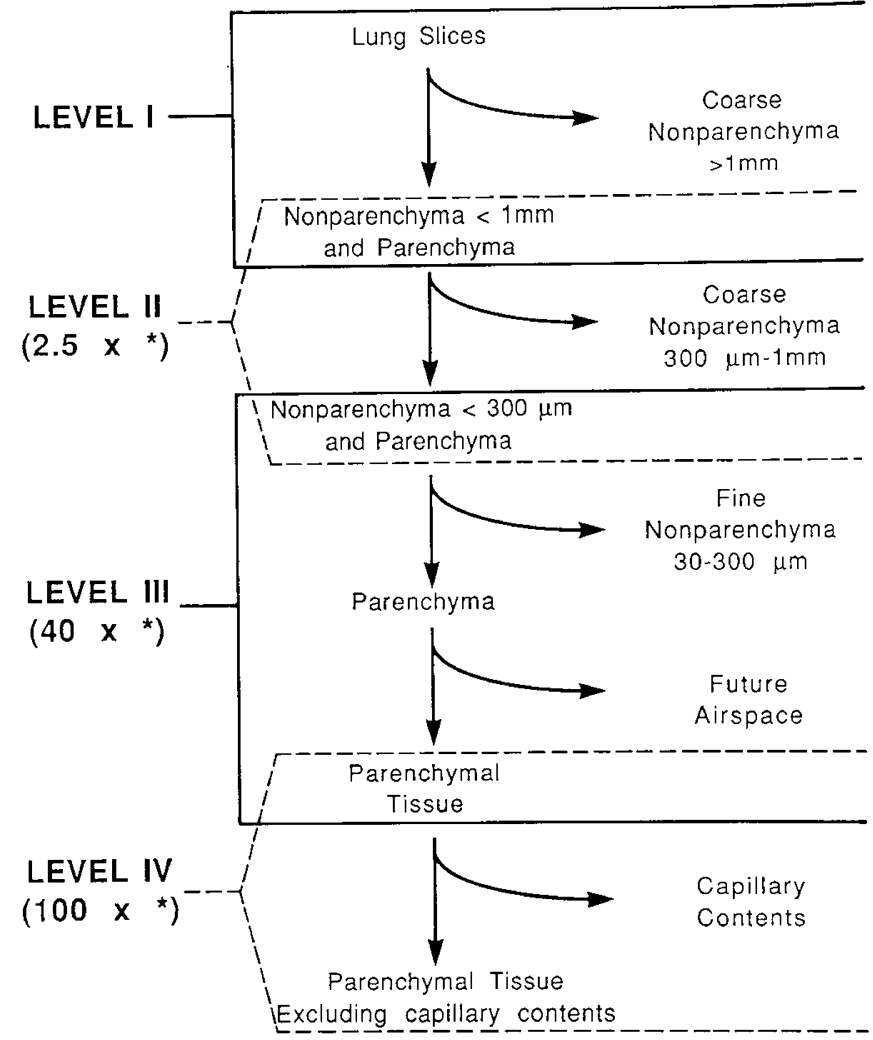

Fig. 1. Four level sampling cascade for determining pulmonary tissue volumes by morphometry. Each level was defined by the tissue component that could be accurately measured at a given magnification. Level I was gross examination of slides of whole lung slices. Point counting was done at each level to determine the number of points falling on the tissue component of interest (e.g. level II-coarse nonparenchyma 300 $\mu \mathrm{m}-1 \mathrm{~mm}$ ) and the total number of points containing the tissue component (e.g. level II-nonparenchyma $<1 \mathrm{~mm}$ and parenchyma). Volume density was calculated by dividing the number of points on the tissue component of interest by the total number of points containing the tissue component. Absolute volumes of each tissue component were then calculated by serially multiplying the volume densities obtained and the displacement volume of the fixed lung. ${ }^{*}$ Microscope objective used to examine tissue sections.

to $1-\mu \mathrm{m}$ thickness. The number of fields counted at each level was chosen to allow the SEM to be $<10 \%$ (17). The volume density of each tissue component was calculated as the number of points falling on the tissue component of interest (e.g. level III-future airspace) divided by the total number of points on the space containing the tissue component (e.g. level III-parenchyma). Absolute volumes were then calculated by serially multiplying the volume densities obtained by point counting and the displacement volume of the fixed lung (18). This sampling scheme resulted in an average total of 12000 points for the left upper lobe and 16000 points for the left lower lobe.

For two lungs, displacement volumes were not available. They were estimated from vol/wt ratios of the other lungs in the same group. The relative proportion occupied by the upper and lower lobe was determined for each individual lung using the proportion of points on the respective lobe at level I (number of points on lobe/total number of points counted). Thus, the total lung volume was divided between the upper and lower lobe. In addition, for comparison with published data $(4,7-9)$ volume percent of the total lobar volume was calculated by dividing the absolute volume by the total lobar volume. For five of the 16 fetuses, it was necessary to reconstruct the volume proportion of coarse nonparenchyma $>1 \mathrm{~mm}$ from the mean volume propor- 
Table 1. Lung wt and displacement volumes in fetal sheep*

\begin{tabular}{|c|c|c|c|c|}
\hline & \multicolumn{2}{|c|}{ Wet wt } & \multirow[b]{2}{*}{ Dry wt $(\mathrm{g})$} & \multirow[b]{2}{*}{$\begin{array}{l}\text { Lung volume } \\
\text { (mL) }\end{array}$} \\
\hline & Absolute (g) & $\begin{array}{c}\% \text { Body } \\
\text { wt }\end{array}$ & & \\
\hline \multicolumn{5}{|l|}{ Left lung } \\
\hline LPA Lig & $28.3(10.5) \dagger^{a b}$ & $0.6(0.2)^{a c d}$ & $3.5(1.2)^{a d}$ & $29.3(10.3)^{a b c}$ \\
\hline Sham & $50.4(9.9)^{a}$ & $1.2(0.2)^{c}$ & $6.5(1.0)^{a}$ & $50.9(9.2)^{a}$ \\
\hline $112 \mathrm{~d}$ Con & $45.4(5.3)^{a}$ & $3.4(0.8)^{a}$ & $4.4(0.7)^{a}$ & $45.8(4.1)^{a}$ \\
\hline $140 \mathrm{~d}$ Con & $81.2(19.9)$ & $1.7(0.3)$ & $9.4(3.0)$ & $77.4(17.8)$ \\
\hline \multicolumn{5}{|l|}{ Right lung } \\
\hline LPA Lig & $102.6(25.2)^{a c}$ & $2.2(0.3)^{a c}$ & $12.1(3.0)^{c}$ & $100.6(23.8)^{a c}$ \\
\hline Sham & $84.8(2.5)^{a c}$ & $2.1(0.3)^{a c}$ & $10.3(1.1)^{c}$ & $83.4(4.0)^{a c}$ \\
\hline $112 \mathrm{~d}$ Con & $50.5(6.5)^{a}$ & $3.8(0.3)^{a}$ & $5.1(1.2)^{a}$ & $37.2(15.6)^{a}$ \\
\hline $140 \mathrm{~d}$ Con & $135.5(24.9)$ & $2.9(0.3)$ & $13.8(1.7)$ & $129.4(25.7)$ \\
\hline
\end{tabular}

* The four groups of fetuses are: LPA lig, left pulmonary artery ligated; sham, sham operated; 112-d con, normal 112-d controls; and 140-d con, normal 140-d controls. $n=$ four in all groups except LPA ligated where $n=$ five. Values are mean (SD). Statistical analysis is one-way analysis of variance with Newman-Keuls multiple range test (NK).

$\dagger^{a} p<0.05$ when compared to $140 \mathrm{~d}$ con by NK; ${ }^{b} p<0.05$ when compared to sham operated by NK; ${ }^{c} p<0.05$ when compared to $112 \mathrm{~d}$ con by NK; ${ }^{d} p<0.06$ when compared to sham operated by NK. tion obtained from other fetuses in the same group (LPA ligation, sham operated, 112-d control, 140-d control).

Data analysis. The values for several variables from each group (LPA ligated, sham operated, 112-d control, and 140-d control) were compared using one-way analysis of variance and the Newman-Keuls multiple range test (19). The variables analyzed were body wt, volume of lung fluid removed at delivery, right and left lung wt (absolute wet wt, percent body wt, and dry wt), right and left total lung volume, and left lung morphometric volumes of coarse nonparenchyma, fine nonparenchyma, future airspace, parenchymal tissue, and capillary contents expressed as $\mathrm{mL}$ and as percent lobar volume.

\section{RESULTS}

There were no differences in body wt between fetuses delivered at $140 \mathrm{~d}$ [mean (SD): LPA ligated, 4.7 (0.7), sham operated, 4.1 $(0.6)$, and $140-\mathrm{d}$ control, $4.7(0.3) \mathrm{kg}$. The amount of lung fluid obtained from the trachea at delivery was also not significantly different among the groups [mean (SD): LPA ligated, $38(20)$, sham operated, 34 (5), 112-d control, 24 (8), and 140-d control, $59(26) \mathrm{mL}$.

Normal growth between 112 and $140 \mathrm{~d}$. Normal growth between 112 and $140 \mathrm{~d}$ resulted in significant increases in all lung wt except wet wt as a percent of body wt: for the left lung-

Table 2. Absolute morphometric volumes $(m L)$ of left lung in fetal sheep*

\begin{tabular}{|c|c|c|c|c|c|}
\hline & $\begin{array}{c}\text { Coarse } \\
\text { nonparenchyma } \\
>300 \mu \mathrm{m}\end{array}$ & $\begin{array}{c}\text { Fine } \\
\text { nonparenchyma } \\
30-300 \mu \mathrm{m}\end{array}$ & $\begin{array}{l}\text { Future } \\
\text { airspace }\end{array}$ & $\begin{array}{l}\text { Parenchymal } \\
\text { tissue }\end{array}$ & $\begin{array}{l}\text { Capillary } \\
\text { contents }\end{array}$ \\
\hline \multicolumn{6}{|l|}{ Upper lobe } \\
\hline LPA Lig & $3.8(0.9)$ & $1.2(0.3) \dagger^{a d}$ & $3.6(2.0)^{a b}$ & $2.0(1.3)^{a b c}$ & $0.4(0.2)^{b e}$ \\
\hline Sham & $3.0(1.9)$ & $1.6(0.3)^{c}$ & $9.0(3.2)$ & $5.7(0.8)$ & $1.5(0.5)^{c}$ \\
\hline $112 \mathrm{~d}$ Con & $2.6(0.5)$ & $1.0(0.2)^{a}$ & $5.6(0.8)^{a}$ & $4.3(0.9)$ & $0.4(0.2)^{a}$ \\
\hline 140d Con & $2.8(0.7)$ & $1.5(0.2)$ & $12.9(3.9)$ & $6.4(2.1)$ & $1.5(1.0)$ \\
\hline \multicolumn{6}{|l|}{ Lower lobe } \\
\hline LPA Lig & $7.3(2.9)$ & $1.7(0.2)$ & $7.7(7.3)^{a}$ & $3.4(1.2)^{a b c}$ & $0.6(0.2)^{a b}$ \\
\hline Sham & $5.3(1.6)$ & $2.2(0.6)$ & $14.0(1.2)^{a}$ & $9.9(4.3)$ & $2.7(1.4)$ \\
\hline $112 \mathrm{~d}$ Con & $4.5(2.3)$ & $2.5(0.6)$ & $13.6(2.3)^{a}$ & $11.5(3.0)$ & $1.2(0.5)^{a d}$ \\
\hline $140 \mathrm{~d}$ Con & $6.3(2.4)$ & $3.2(0.8)$ & $30.2(7.7)$ & $14.2(2.9)$ & $3.3(1.2)$ \\
\hline
\end{tabular}

* The four groups of fetuses are: LPA lig, left pulmonary artery ligated; sham, sham operated; 112-d con, normal 112-d controls; and 140-d con, normal 140-d controls. $n=4$ in each group. Values are mean (SD). Statistical analysis is one-way analysis of variance with the Newman-Keuls multiple range test $(\mathrm{NK})$.

$\dagger^{a} p<0.05$ when compared to $140 \mathrm{~d}$ con by NK; ${ }^{b} p<0.05$ when compared to sham by NK; ${ }^{c} p<0.05$ when compared to $112 \mathrm{~d}$ con by NK; ${ }^{d} p$ $<0.06$ when compared to sham by NK; ${ }^{e} p<0.06$ when compared to $140 \mathrm{~d}$ con by NK.

Table 3. Morphometric volumes in left lung of fetal sheep expressed as \% of total lobar volume*

\begin{tabular}{clcccc}
\hline & $\begin{array}{c}\text { Coarse } \\
\text { nonparenchyma } \\
(>300 \mu \mathrm{m})\end{array}$ & $\begin{array}{c}\text { Fine } \\
\text { Nonparenchyma } \\
(30-300 \mu \mathrm{m})\end{array}$ & $\begin{array}{c}\text { Future } \\
\text { airspace }\end{array}$ & $\begin{array}{c}\text { Parenchymal } \\
\text { tissue }\end{array}$ & $\begin{array}{c}\text { Capillary } \\
\text { contents }\end{array}$ \\
\hline Upper lobe & & & & & \\
LPA Lig & $37.8(13.8) \dagger^{a b c}$ & $11.3(1.9)$ & $32.3(11.7)^{a b}$ & $18.5(7.7)$ & $3.3(1.5)^{b}$ \\
Sham & $14.8(5.4)$ & $8.6(2.6)$ & $45.8(5.3)$ & $30.8(7.7)$ & $8.0(3.0)^{c}$ \\
112d Con & $19.4(3.1)$ & $7.8(1.7)$ & $41.4(5.5)$ & $31.5(6.3)$ & $2.8(1.6)$ \\
140d Con & $11.9(1.2)$ & $6.9(2.3)$ & $54.6(1.6)$ & $26.6(2.2)$ & $6.1(2.0)$ \\
Lower lobe & & & & & \\
LPA Lig & $39.4(16.6)^{a b c}$ & $9.3(2.8)$ & $34.2(19.6)$ & $17.1(4.2)^{a b c}$ & $3.3(1.0)^{b}$ \\
Sham & $16.8(2.0)$ & $7.0(1.2)$ & $45.9(9.1)$ & $30.3(7.9)$ & $8.2(2.8)^{c}$ \\
112d Con & $13.6(5.8)$ & $7.9(1.9)$ & $43.1(11.3)$ & $35.4(6.4)$ & $3.8(1.5)$ \\
140d Con & $11.7(4.3)$ & $6.2(2.1)$ & $55.7(4.6)$ & $26.4(1.0)$ & $5.9(1.0)$ \\
\hline
\end{tabular}

* The four groups of fetuses are: LPA lig, left pulmonary artery ligated; sham, sham operated; 112-d con, normal 112-d controls; and 140-d connormal $140-\mathrm{d}$ controls. $n=4$ in all groups. Values are mean (SD). Statistical analysis is one-way analysis of variance with Newman-Keuls multiple range test $(\mathrm{NK})$

$\dagger^{a} p<0.05$ compared to $140 \mathrm{~d}$ con by NK; ${ }^{b} p<0.05$ compared to sham by NK; ${ }^{c} p<0.05$ compared to $112 \mathrm{~d}$ control by NK. 
increases of $80 \%$ in wet wt $(\mathrm{g}), 110 \%$ in dry wt, and $70 \%$ in lung volume; for the right lung-increases of $170 \%$ in wet $(\mathrm{g})$ and dry wt, and $250 \%$ in lung volume (Table 1). Analysis of left lung tissue volumes revealed increases in all volumes except coarse nonparemchyma, with significant increases in future airspace $(125 \%)$ and capillary contents $(200 \%$, Table 2$)$.

Effect of LPA ligation. LPA-ligated left lungs were significantly smaller in all weights and volumes than those of sham operated or 140-d controls (Table 1). The right lungs after LPA ligation were not significantly different from sham-operated right lungs. However, both LPA-ligated and sham-operated right lungs were significantly larger than in 112-d controls, but smaller than those of 140-d controls (Table 1).

Significant reductions in volumes of fine nonparenchyma, future airspace, parenchymal tissue, and capillary contents occurred with LPA ligation compared to both sham operated and 140-d controls (Table 2). Parenchymal tissue volume in LPAligated fetuses was also significantly less than in 112-d controls. Future airspace and parenchymal tissue volumes were consistently less in sham-operated fetuses than in 140-d controls, but the difference reached statistical significance only for lower lobe future airspace.

Expressing morphometric volumes as a percent of total lobar volume revealed a significant increase in the volume proportion of coarse nonparenchyma in LPA-ligated lungs compared to all other groups (Table 3). Although future airspace and parenchymal tissue proportions were decreased in both lobes by LPA ligation, statistical analysis revealed significant decreases in future airspace in the upper lobe and in parenchymal tissue in the lower lobe (Table 3). Volume proportion of capillary contents was also significantly lower in LPA-ligated than sham-operated fetuses.

Histologic description. LPA ligation caused obvious hypoplasia of the left lung (Fig. 2). Major differences between the groups were evident in the lung parenchyma. In all groups, bronchial walls were well developed, containing submucosal glands, cartilage, and blood vessels in their fibromuscular sheath. Bronchioles had well-developed cuboidal epithelium and were typically star shaped in cross-section. In the 112-d controls, future airspace walls contained a double layer of capillaries and thick epithelial and interstitial cells (Fig. $3 B$ ). Alveolar ducts were lined by shallow, thick septa with few capillaries easily identified (Fig. $3 A$ ). Lungs of the LPA ligation group were similar to those of 112-d controls but showed thick fibrous bands containing airways and blood vessels coursing through the parenchyma (Fig. $3 C$ ). Alveolar duct and septal walls showed great variability with many areas containing thick, double capillary walls and few areas showing attenuated, single capillary walls (Fig. 3D). At 140-d gestation, both control and sham-operated fetuses showed typical thin, single capillary alveolar and ductal walls (Fig. $3 E$ to $H$ ).

The pulmonary arteries and capillaries of the LPA-ligated lungs appeared patent and contained blood cells (Fig. $3 D$ ). There was no evidence of intimal fibrosis or thickening, medial proliferation, or smooth muscle hypertrophy in either the pulmonary or bronchial arteries accompanying the larger airways $(>200 \mu \mathrm{m}$ internal diameter). However, there did appear to be an increased number of bronchial blood vessels in the adventitia of larger airways. The preparation of lung tissue for this study did not include injection of the pulmonary or bronchial arteries and therefore it was impossible to clearly distinguish small pulmonary and bronchial arteries, the source of blood in the small arteries, or the level of anastomosis between the pulmonary and bronchial circulations.

\section{DISCUSSION}

LPA ligation greatly alters growth of the left lung causing significant hypoplasia. The reduction in size is due to a decrease in the volume of the future gas exchange portion of the lung: future airspaces and parenchymal tissue. Changes in the number of airways (nonparenchyma) were not expected because LPA
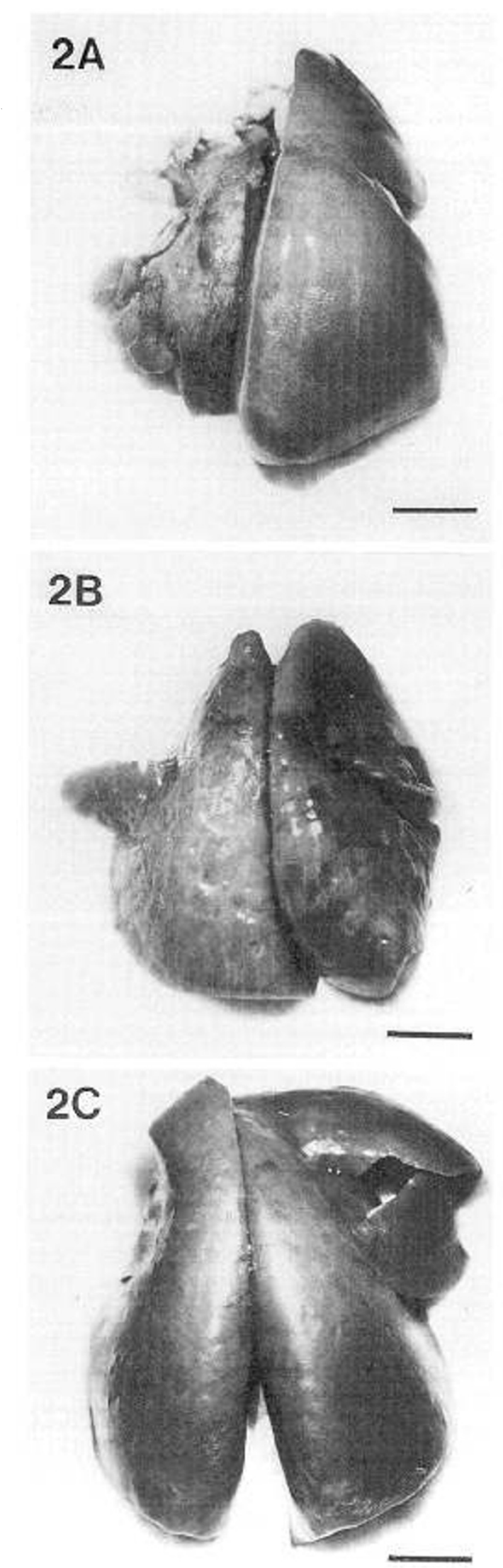

Fig. 2. Dorsal view of left lungs removed from three fetal sheep at 140-d gestation. $A$, LPA ligation performed at $113-\mathrm{d}$ gestation grossly decreases the size of the left lung (fetal wt $5.25 \mathrm{~kg}$ ); $B$, sham operation performed at 114-d gestation (fetal wt $3.77 \mathrm{~kg}$ ); and $C$, unoperated 140 d control lungs (fetal wt $4.78 \mathrm{~kg}$ ). Scale bar indicates $2 \mathrm{~cm}$ in all photographs. 

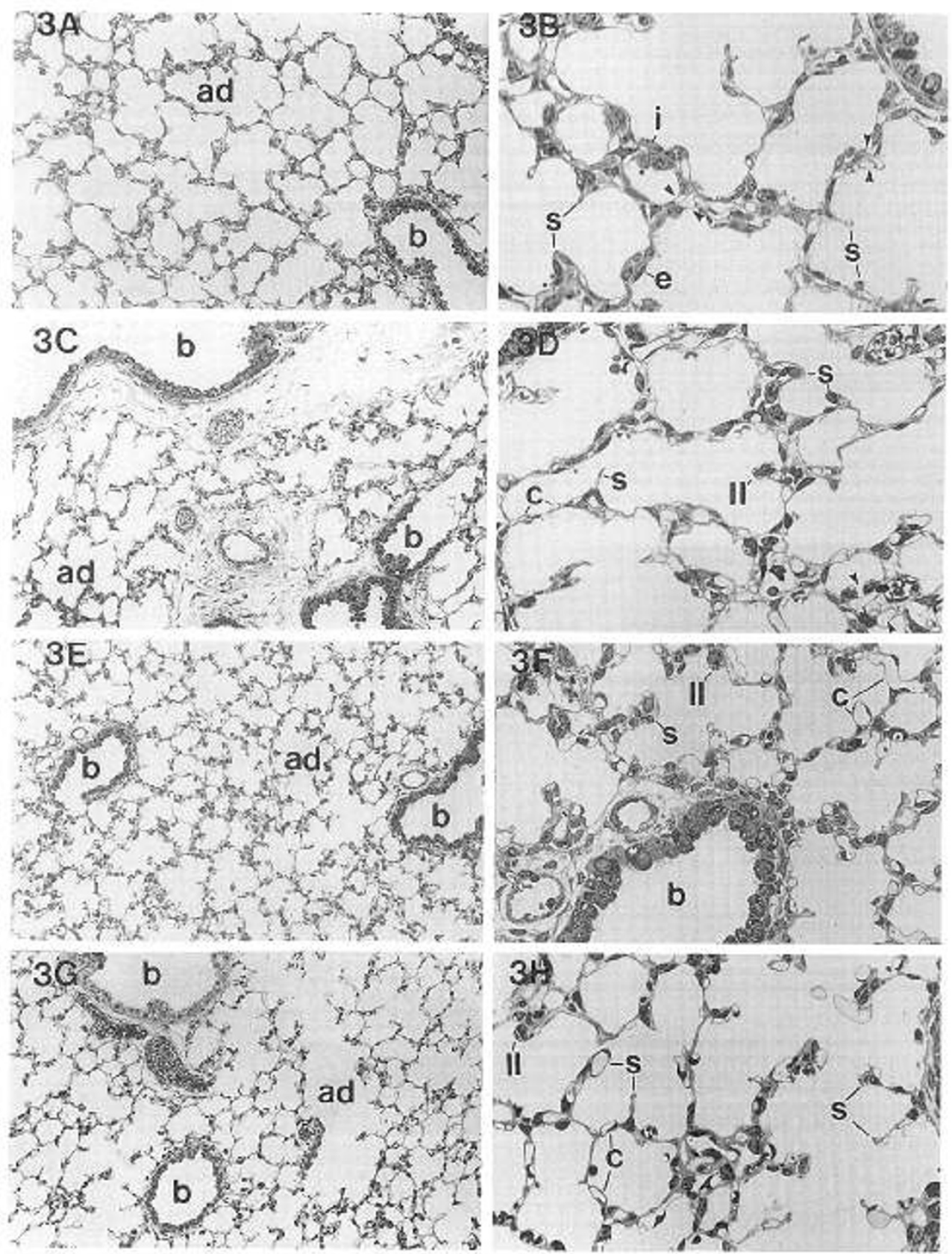

Fig. 3. Microscopic sections from left lungs of fetal sheep at low $(160 \times ; A, C, E, G)$ and high $(560 \times ; B, D, F, H)$ magnification. $A$ and $B$, 112-d unoperated controls showing few thick, alveolar walls. $C$ and $D$, LPA ligated showing a thick fibrous band containing airways and blood vessels, and sparse alveolar walls. $E$ and $F$, sham operated showing thin alveolar walls. $G$ and $H, 140$-d unoperated controls showing thin alveolar walls with many septa. Abbreviations: $a d$, alveolar duct; $b$, bronchiole; $i$, interstitium; $e$, epithelium; $s$, septum; arrowheads, double capillary wall; $c$, single capillary wall; $I I$, type II cell.

ligation was performed during the late canalicular stage, a time when large airways and blood vessels are no longer forming (15, 20).

The results of past studies on the effect of pulmonary artery ligation on lung growth are contradictory. In humans, decreased pulmonary flow with absent or hypoplastic pulmonary arteries presumably occurs in the fetal pseudoglandular (airway development) or canalicular stage of growth and is associated with reduced lung volume, decreased alveolar number, and in two cases reduced airway number (11). In fetal sheep, LPA ligation at 83-135 d gestation (canalicular to alveolar stage) was reported not to affect lung growth; this result is probably due to the wide range of gestational ages at which LPA ligation was done (13). A similar procedure in fetal rabbits at 25-29 d gestation (canalicular stage) produced pulmonary necrosis (14). In newborn pigs, LPA ligation caused a reversible decrease in left lung volume and alveolar number (21). Thus, the type and degree of pulmonary hypoplasia as a result of impaired lung perfusion depends on the timing of the insult.

This study contains the first report of absolute morphometric volumes in a fetal sheep model of pulmonary hypoplasia. Strict adherence to the methods of stereologic morphometry (16-18) ensures accurate sampling of the inhomogeneous lung tissue and allows quantitation of all tissue volumes. In addition, as the number of points counted was chosen to ensure a SEM less than $10 \%$ (17), generalization of these results can be done with confidence. Although absolute lung volumes have not been reported, other models of hypoplasia in the fetal sheep have been mor- 
phometricaly examined (4, 7-9). The technique of fixation, definitions of tissue components, and timing of intervention differ among these studies making comparisons difficult. However, all of these models cause reduction in the volume percent of the future airspace expressed here as the difference in volume percent between control and experimental animals: diaphragmatic hernia, $27 \%$ (4); tracheal drainage, $18 \%$ (7); tracheostomy, $14 \%$ (8); and phrenectomy, $12 \%(9)$. Our study shows a $22 \%$ decrease in future airspace (Table 3), an effect at least as great as that seen in other models. Although the effect of the above interventions on pulmonary arterial flow is not known, the possible reduction of pulmonary arterial flow as a cause of hypoplasia in these models should be considered.

The way in which pulmonary arterial flow contributes to fetal lung growth is unknown. In fetal sheep the pulmonary artery receives only $3-7 \%$ of the combined ventricular output (22), but pulmonary blood flow increases steadily in late gestation and pulmonary oxygen delivery and glucose consumption remain high (23). Thus, interruption of pulmonary arterial flow may decrease nutrient delivery or delivery of circulating hormones necessary for normal growth (24). Lung liquid volume and fetal breathing movements are known to be important for lung growth, but their relationship to pulmonary arterial flow is unknown. Changes in lung fluid volume can affect pulmonary blood flow (25) and perhaps decreased lung fluid volume $(7,8)$ decreases pulmonary blood flow. Further investigation is necessary to determine the mechanisms through which decreased pulmonary arterial flow disturbs fetal lung growth.

The contribution of the bronchial circulation to the blood supply of the ligated lung cannot be determined from our study. All blood vessels examined contained blood cells, implying the existence of collateral circulation. Study of the bronchial collateral circulation in newborn pigs after LPA ligation, revealed that histologic changes were not apparent until 8 wk after LPA ligation (26). In this study, only 4-5 wk were allowed for development of collateral circulation, making it impossible to determine the extent of its development by histologic examination without injection of the bronchial arteries. This model is also not similar to pulmonary atresia where pulmonary perfusion is provided by the ductus arteriosus and large systemic arteries (27). Clearly, the development of collateral circulation after LPA ligation in fetal sheep was not sufficient to allow for normal lung growth.

In summary, LPA ligation during the late canalicular stage of fetal lung development creates pulmonary hypoplasia with significantly decreased lung wt and displacement volume. Morphometric analysis reveals reduction in volumes of fine nonparenchyma, future airspace, parenchymal tissue, and capillary contents after LPA ligation. Pulmonary arterial flow must be considered in evaluation of factors associated with pulmonary hypoplasia.

Acknowledgments. The authors thank Joseph Kitterman for his support and encouragement of this work and Allena McSkimming for preparation of this manuscript.

\section{REFERENCES}

1. Blanc WA 1981 General discussion. In: Elliott K, Whelam J (eds) The Fetus and Independent Life. Ciba Symposium 86. London, Pitman, pp 332-333

Wigglesworth JS, Desai R 1982 Is fetal respiratory function a major determinant of perinatal survival? Lancet 1:264-267

3. Kitterman JA 1986 Physical factors and fetal lung growth. In: Johnston BM and Gluckman PD (eds) Respiratory Control and Lung Development in the Fetus and Newborn. Perinatology Press, Ithaca, NY, pp 63-85

4. de Lorimier AA, Manus AG, Tyler WS 1969 Morphometry of normal and hypoplastic lungs in newborn lambs. Curr Top Surg Res 1:431-442

5. Pringle KC Turner JW, Schofield JC, Soper RT 1984 Creation and repair of diaphragmatic hernia in the fetal lamb: lung development and morphology. J Pediatr Surgery 19:131-140

6. Moessinger AC, Collins MH, Blanc WA, Rey HR, James LS 1986 Oligohydramnios-induced lung hypoplasia: the influence of timing and duration in gestation. Pediatr Res 20:951-954

7. Alcorn DG, Adamson TM, Lambert TF, Maloney JE, Ritchie BC, Robinson PM 1977 Morphological effects of chronic tracheal ligation and drainage in the fetal lamb lung. J Anat 123:649-660

8. Fewell JE, Hislop AA, Kitterman JA, Johnson P 1983 Effect of tracheostomy on lung development in fetal lambs. J Appl Physiol 55:1 103-1 108

9. Alcorn DG, Adamson TM, Maloney JE, Robinson PM 1980 Morphological effects of chronic bilateral phrenectomy or vagotomy in the fetal lamb lung. J Anat 130:683-695

10. Liggins GC, Vilos GA, Campos GA, Kitterman JA, Lee CH 1981 The effect of spinal cord transection on lung development in fetal sheep. J Dev Physiol $3: 267-274$

11. Hislop A, Sanderson M, Reid L 1973 Unilateral congenital dysplasia of lung associated with vascular anomalies. Thorax 28:435-441

12. Werber J, Ramilo JL, London R, Harris VJ 1983 Unilateral absence of a pulmonary artery. Chest 84:729-732

13. Pickard LR, Tepas III JJ, Inon A, Hutchins GM, Shermeta DW, Haller JA 1979 Effect of pulmonary artery ligation on the developing fetal lung. Am Surg 45:793-796

14. Thomasson B, Kero P, Lansimies E, Toikkanen S, Valimaki I 1979 Pulmonary aeration after unilateral fetal ligation of pulmonary artery in neonatal rabbits. Biol Neonate 36:92-98

15. Alcorn DG, Adamson TM, Maloney JE, Robinson PM 1981 A morphologic and morphometric analysis of fetal lung development in the sheep. Anat Record 201:655-667

16. Weibel ER 1984 Morphometric and stereological methods in respiratory physiology, including fixation techniques. Respir Physiol P401:1-35

17. Weibel ER 1979 Stereological Methods, Vol 1. Practical Methods for Biological Morphometry. Academic Press, New York, pp 101-161

18. Cruz-Orive LM, Weibel ER 1981 Sampling designs for stereology. J Microsc $122: 235-257$

19. Zar J 1974 Multiple comparisons. In: Biostatistical Analysis. Prentice-Hall Englewood Cliffs, NJ, pp 151-162

20. Langston C, Kida K, Reed M, Thurlbeck WM 1984 Human lung growth in late gestation and in the neonate. Am Rev Respir Dis 129:607-613

1. Haworth SG, McKenzie SA, Fitzpatrick ML 1981 Alveolar development after ligation of left pulmonary artery in newborn pig: clinical relevance to unilateral pulmonary artery. Thorax 36:938-943

22. Rudolph AM, Heymann MA 1970 Circulatory changes during growth in the fetal lamb. Circ Res 26:289-299

23. Simmons RA, Charlton VE 1988 Substrate utilization by the fetal sheep lung during the last trimester. Pediatr Res 23:606-611

24. Schellenberg JC, Liggins GC, Kitterman JA, Lee CH 1987 Elastin and collagen in the fetal sheep lung. II. Relationship to mechanical properties of the lung. Pediatr Res 22:339-343

25. Walker AM, Ritchie BC Adamson TM, Maloney JE 1988 Effect of changing lung liquid volume on the pulmonary circulation of fetal lambs. $J$ Appl Physiol 64:61-67

26. Haworth SG, deLeval M, Macartney FJ 1981 How the left lung is perfused after ligating the left pulmonary artery in the pig at birth: clinical implications for the hypoperfused lung. Cardiovasc Res 15:214-226

27. Jefferson K, Rees S, Somerville J 1972 Systemic arterial supply to the lungs in pulmonary atresia and its relation to pulmonary artery development. B Heart J 34:418-427 